\section{Faktor-faktor yang berhubungan dengan persepsi body image pada tenaga kesehatan di RSUD Meuraxa}

\author{
Factors related to the perception of body image in \\ health workers at Meuraxa hospital
}

SAGO: Gizi dan Kesehatan 2020, Vol. 2(1) $60-70$ (C) The Author(s) 2020

DOI: http://dx.doi.org/ 10.30867/gikes.v2i1.466 https://ejournal.poltekkesaceh.ac.id/index.php/

Poltekkes Kemenkes Aceh

\author{
Alfian ${ }^{1}$, Asnawi Abdullah ${ }^{2}$, Nurjannah ${ }^{3}$
}

\begin{abstract}
Background: Body image reflects a person's health status, for health workers body image can describe professionalism. Health workers should be able to give a role models for hospital visitors in the health sector, especially in maintaining optimal body image.

Objectives: This study aims to determine the factors associated with the perception of body image in health workers at Meuraxa Hospital, Banda Aceh City.

Methods: This research was conducted by analytic descriptive with cross-sectional design. Data were collected using a questionnaire. The population in this study were all health workers at Meuraxa Hospital, amounting to 375 people. The sample size was taken based on the provisions of Krejcie and Morgan's statutory table, as many as 191 people. The statistical test used was logistic regression and was analyzed using the stata 14.

Results: Perceptions of negative body image were more common in women (64.10\%), and at the age of 25-29 years $(70.18 \%)$. Factors related to the body image of health workers were gender $(p=0.004)$, food consumption behavior $(p=$ $0.001)$, interpersonal relationships $(p=0.021)$. Meanwhile, age and medical conditions did not show a relationship with body image. The dominant factor causing body image is consumption behavior.

Conclusion: The factors related to the body image of health workers are gender, food consumption behavior, and interpersonal relationships. While the dominant factor is food consumption behavior.
\end{abstract}

\title{
Keywords:
}

Body image, consumption behavior, health workers

\section{Abstrak}

Latar Belakang: Body image mencerminkan status kesehatan seseorang, bagi tenaga kesehatan body image dapat menggambarkan profesionalisme. Tenaga kesehatan sudah seharusnya bisa memberikan kesan yang baik (role model) bagi pengunjung rumah sakit dalam bidang kesehatan terutama dalam menjaga body image agar tetap optimal.

Tujuan: Untuk mengetahui faktor-faktor yang berhubungan dengan persepsi body image pada tenaga kesehatan di RSUD Meuraxa Kota Banda Aceh.

Metode: Penelitian dilakukan secara deskriptif analitik dengan desain cross-sectional. Data dikumpulkan menggunakan kuesioner. Populasi dalam penelitian ini adalah seluruh tenaga kesehatan di RSUD Meuraxa yang berjumlah 375 orang. Besaran sampel diambil berdasarkan ketetapan tabel ketetapan Krejcie dan Morgan yaitu sebanyak 191 orang. Uji statistik yang digunakan adalah regresi logistik dan di analisa menggunakan aplikasi stata 14.

\footnotetext{
1 Program Studi Magister Kesehatan Masyarakat, Fakultas Kesehatan Masyarakat, Universitas Muhammadiyah, Aceh E-mail: alfiandhiauddin@gmail.com

2 Program Studi Magister Kesehatan Masyarakat, Fakultas Kesehatan Masyarakat, Universitas Muhammadiyah Aceh, Indonesia. E-mail: Asnawi.Abdullah@gmail.com

3 IImu Kesehatan Masyarakat, Fakultas Kedokteran, Universitas Syiah Kuala, Aceh, Indonesia. E-mail: nurjannah_dr@unsyiah.ac.id
}

Penulis Koresponding:

Alfian: Jl. Muhammadiyah No.91, Batoh, Kecamatan Lueng Bata. Program Studi Magister Kesehatan Masyarakat, Fakultas Kesehatan Masyarakat, Universitas Muhammadiyah, Aceh E-mail: alfiandhiauddin@gmail.com 
Hasil: Persepsi body image negatif lebih banyak ditemukan pada perempuan (64.10\%), dan pada usia 25-29 tahun (70.18\%). Faktor-faktor yang berhubungan dengan body image tenaga kesehatan yaitu faktor jenis kelamin $(p=0.004)$, perilaku konsumsi makanan ( $p=0.001)$, hubungan interpersonal $(p=0.021)$. Sedangkan faktor umur dan kondisi medis tidak menunjukkan hubungan dengan body image. Faktor dominan penyebab body image yaitu perilaku konsumsi.

Kesimpulan: Faktor-faktor yang berhubungan dengan body image tenaga kesehatan yaitu faktor jenis kelamin, perilaku konsumsi makanan, hubungan interpersonal. Sedangkan faktor dominan yaitu perilaku konsumsi makanan.

\section{Kata Kunci}

Body image, perilaku konsumsi, tenaga kesehatan

\section{Pendahuluan}

$B$ ody image merupakan bagian dari konsep diri yang berupa gambaran seseorang mengenai tubuhnya (Atwater et al., 2005). Menurut Thompson et al. (1999) melihat citra tubuh sebagai penampilan sebenarnya atau bagaimana melihat orang lain, bagaimana pandangan sendiri untuk tampil terhadap orang lain dan representasi internal dari tampilan luar, persepsi dari tubuh dan tampilan internal terkait dengan pemikiran dan perasaan dan bisa saja merubah perilaku pada situasi tertentu.

Prevalensi kasus obesitas dan kelebihan berat badan terus meningkat setiap tahun (Roberts et al., 2013). Pada sekitar $73 \%$ pekerja kesehatan menderita obesitas dan kelebihan berat badan (Skall \& Pengpid, 2011), di mana 44,4\% dari mereka adalah wanita dan $7,9 \%$ adalah pria. Data ini didukung dari penelitian yang dilakukan oleh Abbate et al. (2006) yang menunjukkan $13,6 \%$ wanita dan $13,3 \%$ pria menderita obesitas dan kelebihan berat badan. Penelitian yang dilakukan oleh Nunez et al. (2005) menunjukkan bahwa tenaga kesehatan wanita lebih berisiko menderita obesitas dan kelebihan berat badan sebesar 75\% daripada pria. Citra tubuh adalah penampilan fisik yang terkait dengan berat badan, yang dinilai dalam setidaknya tiga komponen terpisah dari citra tubuh yaitu persepsi ukuran tubuh, komponen aspek subyektif dan perilaku yang akan menentukan hasil penilaian subyektif (Heinberg et al., 1995). Citra tubuh dari perspektif kesehatan masih dianggap sebagai masalah sensitif (Gila et al., 2004).

Menurut Bert and Panek (1989) bahwa "perubahan fisik yang terjadi selama masa dewasa madya mungkin sangat sulit bagi beberapa wanita, karena masyarakat memandang seorang wanita harus terlihat cantik dan muda dalam penampilannya akibat fisik dari penuaan dapat menurunkan nilai dan harga diri, karena mereka menerima mitos bahwa penurunan kecantikan fisik berarti sesuatu yang negatif".

Survei nasional yang dilakukan di Amerika Serikat diketahui setengah dari 805 wanita mengevaluasi citra tubuh secara negatif dan mengaku ketidakpuasan terhadap penampilannya (Cash \& Henry, 1995). Wanita dewasa memandang citra tubuh lebih negatif jika dibandingkan laki-laki dewasa karena mereka cenderung memelihara dan merawat penampilan (Hubley \& Quinlan, 2003).

Santrock (2002) menemukan bahwa perempuan dewasa madya lebih memfokuskan perhatian pada daya tarik wajah daripada perempuan yang lebih tua atau lebih muda. Perempuan dewasa madya lebih mungkin menganggap tanda-tanda penuaan sebagai memiliki pengaruh negatif terhadap penampilan fisiknya.

Penelitian oleh Ziebland et al. (2002) diketahui bahwa $87 \%$ (33/38) dari wanita usia 35 sampai 55 tahun selalu mencoba untuk menurunkan berat badan walaupun mereka tidak memiliki kelebihan berat badan dan diberitahukan bahwa $58 \%$ wanita tersebut berhasil menurunkan berat badan mereka. Hal ini disebabkan oleh ketidakpuasaan pada citra tubuh dibandingkan dengan konsekuensi kesehatan.

Hurlock (1980) mengatakan citra tubuh sangat erat kaitannya dengan penampilan fisik seseorang, jika seseorang tersebut merasa dirinya tidak menarik seperti yang diharapkan maka akan mencari jalan keluar untuk memperbaiki dirinya. Kecantikan dan daya tarik fisik sangat penting bagi wanita. Menurut Cash and Pruzinsky (2002) menjelaskan bahwa citra tubuh merupakan representasi mental dari tubuh yang meliputi persepsi dari penampilan, perasaan dan pikiran tentang tubuh, bagaimana rasanya berada di dalam tubuh, dan fungsi tubuh dan kemampuannya.

Beberapa penelitian menemukan bahwa masalah ketidakpuasan terhadap citra tubuh ternyata dapat menimbulkan masalah-masalah lain 
yang lebih serius. Attie dan Brooks-Gunn; Strong dan Huon dalam Haugaard (2001) menyatakan bahwa perempuan yang merasa tidak puas dengan bentuk tubuh mereka akan berisiko lebih tinggi untuk melakukan diet yang serius dan mengalami gangguan makan dibandingkan dengan perempuan yang telah merasa puas dengan bentuk tubuh mereka.

Faktor-faktor yang mempengaruhi perkembangan Body image menurut Cash (1994) adalah jenis kelamin, media massa, hubungan interpersonal. Thompson (2000) mengemukakan faktor-faktor yang mempengaruhi Body image adalah pengaruh berat badan dan persepsi gemuk/kurus, budaya, siklus hidup, masa kehamilan, sosialisasi, konsep diri, peran gender, dan pengaruh distorsi citra tubuh pada diri individu.

Dalam penelitian yang dilakukan oleh Kostanski dan Gulleno dalam Devi and Dian (2015) menyatakan bahwa ketidakpuasaan citra tubuh berhubungan negatif dengan harga diri tetapi ketidakpuasaan citra tubuh berhubungan positif dengan kecemasan dan depresi terhadap massa tubuh. Artinya peningkatan ketidakpuasaan akan diikuti penurunan harga diri dan peningkatan kecemasan dan depresi terhadap massa tubuh. Kecemasan sendiri ternyata memiliki hubungan dengan kepercayaan diri apabila kecemasan tersebut adalah kecemasan komunikasi interpersonal.

Citra tubuh dapat mencerminkan status kesehatan seseorang, sedangkan untuk tenaga kesehatan, citra tubuh dapat menggambarkan profesionalisme, dapat meningkatkan hubungan positif antara konselor dan klien dan keberhasilan dalam memberikan terapi terutama untuk pengendalian berat badan (McArthur \& Ross, 1997). Namun, hasil penelitian menemukan bahwa kesadaran tenaga kesehatan akan gambaran tubuh yang baik akan mempengaruhi empati tenaga kesehatan pada masalah yang terkait dengan bentuk tubuh pasien (Brown et al., 2007; Wright, 1998).

Sejauh ini, memang belum ada penelitian yang spesifik mengenai dampak body image negatif terhadap tenaga kesehatan. Namun demikian, berdasarkan beberapa teori dan asumsi peneliti bahwa body image negatif pada dasarnya akan sangat berpengaruh terhadap kinerja tenaga kesehatan. Hal tersebut dikarenakan, orang yang memiliki body image negatif akan cenderung mengalami hal-hal seperti cemas, depresi, rendah diri, malu, dan sulit berkonsentrasi, sehingga secara tidak langsung berdampak pada kualitas pelayanan kesehatan yang diberikan.

Berdasarkan data laporan RSUD Meuraxa Kota Banda Aceh Tahun 2019 total jumlah tenaga kesehatan yaitu 375 orang yang terdiri dari, 30 Dokter Umum, 1 Dokter Gigi, 56 Perawat Ahli, 4 Apoteker, 177 Perawat, 1 Perawat operator C-Arm, 2 Perawat Gigi, 33 Bidan, 5 Fisioterapi, 1 Refraksionis Optisi Pelaksana, 9 Radiografer, 8 Perekam Medik Pelaksana, 1 Review Status Rekam Medik, 20 Asisten Apoteker, 13 Pranata Laboratorium, 5 Administrator Rekam Medik, 2 Ahli Gizi, 1 Staf Komite Mutu dan Keselamatan Pasien, 2 Administrasi Rawat Inap, 1 Staf Sekretariat Akreditasi, 1 Kesehatan Lingkungan, 1 Teknik Elektro Medik, 1 Adm. Radiologi (RSUD Meuraxa, 2019). Selain itu, tenaga kesehatan yang overweigt atau obesitas di Rumah Sakit Umum Daerah Meuraxa berjumlah 90 orang.

Tenaga kesehatan perlu memiliki kesiapan dalam memberikan pelayanan pada masyarakat terutama dalam bidang kesehatan. Jika tenaga kesehatan dalam keadaan tidak sehat, tentu akan mempengaruhi kualitas pelayanan yang diberikan. Hasil obersevasi awal peneliti melalui wawancara secara acak mengenai body image kepada 20 responden di dapatkan bahwa sebanyak $45 \%$ tenaga kesehatan memiliki persepsi body image negatif. Banyak tenaga kesehatan bermasalah dengan tubuhnya dimana terdapat petugas dengan berat badan yang berlebih, ada juga petugas dengan kondisi sangat kurus. Tenaga kesehatan sudah seharusnya bisa memberikan kesan yang baik (role model) bagi pengunjung rumah sakit dalam bidang kesehatan terutama dalam menjaga Body image agar tetap optimal. Akan tetapi, tenaga kesehatan rumah sakit masih banyak ditemui mempunyai masalah dengan kesehatan seperti kejadian obesitas sentral yang menjadi salah satu masalah bady image pada tenaga kesehatan (Budhiarta \& Muttaqin, 2019).

\section{Metode}

Penelitian ini bersifat observasional deskriptif dengan pendekatan cross sectional study yaitu peneliti melakukan pengukuran dalam waktu yang bersamaan (sekali waktu) (Notoatmodjo, 2003). Dalam penelitian ini peneliti ingin melihat hubungan faktor-faktor yang berhubungan dengan 
persepsi Body image Pada Tenaga Kesehatan di RSUD Meuraxa Kota Banda Aceh. Penelitian ini dilakukan pada bulan Agustus 2020 Pada Tenaga Kesehatan di RSUD Meuraxa Kota Banda Aceh. Populasi dalam penelitian adalah tenaga Kesehatan di RSUD Meuraxa Kota Banda Aceh Tahun 2019 yaitu berjumlah 375 orang. Besar sampel dalam penelitian ini diambil dari tabel ketetapan Krejcie dan Morgan dimana untuk sampel dari populasi sebesar 375 orang adalah 191 orang. Teknik pengambilan sampel dilakukan dengan menggunakan teknik random sampling.

Metode pengumpulan data dibagi kedalam beberapa jenis metode pengumpulan data: Metode wawancara, yaitu peneliti melakukan wawancara dengan kuesioner yang telah disusun sebelumnya. Pada tahap ini, data yang dikumpulkan adalah data karakteristik responden, persepsi body image, kondisi medis, perilaku kesehatan dan hubungan interpersonal. Kedua, metode pengukuran tinggi badan dan berat badan. Metode ini digunakan untuk mengukur Body Mass Indeks (BMI) dengan cara melakukan penimbangan secara langsung kepada responden disertai dengan melakukan pengukuran tinggi badan responden.

Pengolahan data adalah suatu cara pengorganisasian data sehingga didapat konsep, dari konsep tertentu akan berbentuk hubungan (Sumantri, 2011). Langkah pengolahan data adalah sebagai berikut: Editing, peneliti memastikan bahwa data yang diperoleh sudah lengkap atau belum, artinya data dalam kuesioner tersebut telah terisi semua dengan lengkap, jelas dan relevan. Coding, setelah data di isi dengan lengkap dan benar, peneliti memberikan kode pada setiap pertanyaan yang belum sesuai dengan kode untuk memudahkan pada saat analisis data dan juga juga mempercepat pada saat memasukan data ke program komputer. Entry, selanjutnya peneliti memasukan semua data yang telah di edit ke dalam program Stata 14.0

Data yang sudah dikumpulkan selanjutnya akan diperoleh dengan menggunakan software komputer berupa Aplikasi Program Stata 14.0 dan hasilnya akan disajikan dalam bentuk tabel distribusi frekuensi dan narasi. Analisis data dilakukan secara statistik meliputi analisis univariat, bivariat dan multivariat. Proses analisa bivariat dilakukan dengan menggunakan program Stata 14.0 yaitu dengan cara membuat tabel silang antara variabel independen dan variabel dependen. Proses tersebut dilakukan untuk mengetahui besaran persentase antara kategori independen dan dependen, sehingga diketahui kategori mana yang mempunyai persentase tertinggi dari variabel independen dan dependen tersebut. Langkah selanjutnya adalah melakukan uji statistik untuk mengetahui hubungan antara variabel independen dan dependen menggunakan uji regresi logistik sederhana. Penggunaan analisis regresi logistik adalah karena mampu untuk menghitung seberapa besar variabel independen akan mempengaruhi variabel dependen dengan nilai Odds Rasio (OR) yang dihasilkan (Ghozali, 2011). Analisis multivariat digunakan untuk mengetahui apakah masih ada hubungan antara variabel bebas dengan variabel terikat jika variabel bebas lainnya di kontrol. Pada analisis ini uji yang digunakan adalah uji Logistik Regresi ganda dengan menggunakan Stata 14.0.

\section{Hasil}

\section{Karakteristik Responden}

Responden dalam penelitian ini adalah tenaga kesehatan yang bertugas di RSUD Meuraxa Kota Banda Aceh. Sampel dalam penelitan ini sebanyak 191 orang yang diambil berdasarkan nilai ketetapan tabel Krejcie dengan $\mathrm{Cl}$ 95\% dimana dengan populasi 375. Karakteristik responden dapat dilihat melalui dua variabel yaitu jenis kelamin dan kelompok usia.

Tabel 1. Karakteristik responden berdasarkan jenis kelamin dan kelompok usia

\begin{tabular}{|c|c|c|}
\hline Karakteristik & $f$ & $\%$ \\
\hline \multicolumn{3}{|l|}{ Jenis Kelamin } \\
\hline Laki-Laki & 35 & 18.32 \\
\hline Perempuan & 156 & 81.68 \\
\hline \multicolumn{3}{|l|}{ Usia } \\
\hline Di atas 50 Tahun & 2 & 1.05 \\
\hline 45-49 Tahun & 4 & 2.09 \\
\hline 40-44 Tahun & 30 & 15.71 \\
\hline 35-39 Tahun & 42 & 21.99 \\
\hline 30-34 Tahun & 56 & 29.32 \\
\hline 25-29 Tahun & 57 & 29.84 \\
\hline Jumlah & 191 & 100.0 \\
\hline
\end{tabular}

Tabel 1 menunjukkan bahwa responden dengan jenis kelamin perempuan jauh lebih banyak jika dibandingkan dengan responden lakilaki. Secara persentase responden perempuan sebesar $81.68 \%$ sementara responden laki-laki hanya sebesar $18.32 \%$. Selain itu, diketahui juga 
bahwa responden dengan kelompok usia 25-29 tahun lebih banyak jika dibandingkan dengan kelompok usia lainnya. Secara persentase responden kelompok usia 25-29 tahun sebesar $29.84 \%$. Sementara itu, responden dengan jumlah terendah adalah responden pada kelompok usia di atas 50 tahun dengan persentase hanya $1.05 \%$.

\section{Faktor-Faktor yang Berhubungan dengan Body Image}

Hasil penelitian (tabel 2) menunjukkan bahwa persepsi body image kategori positif lebih banyak dijumpai pada jenis kelamin laki-laki dengan persentase $62.9 \%$ jika dibandingkan jenis kelamin perempuan dengan persentase $35.9 \%$. Sementara itu, sebaliknya persepsi body image kategori negatif lebih banyak dijumpai pada jenis kelamin perempuan dengan persentase $64.1 \%$ jika dibandingkan jenis kelamin laki-laki dengan persentase $37.1 \%$. Hasil uji statistik menunjukkan jenis kelamin perempuan berisiko 3 kali mengalami persepsi body image negatif jika dibandingkan dengan laki-laki. Sementara itu nilai $p=0.004$ yang berarti ada hubungan antara jenis kelamin dengan persepsi body image pada tenaga kesehatan di RSUD Meuraxa Banda Aceh.

Berdasarkan kelompok usia, hasil penelitian diketahui bahwa persepsi body image kategori positif lebih banyak dijumpai pada kelompok usia 45-49 tahun jika dibandingkan dengan kelompok usia lainnya. Persentase kelompok usia 45-49 tahun sebesar $75 \%$, dan yang terendah terdapat pada kelompok usia 25-29 tahun sebesar 29.8\%. Sementara itu, sebaliknya persepsi body image kategori negatif lebih banyak dijumpai pada kelompok umur 25-29 tahun jika dibandingkan dengan kelompok umur lainnya. Persentase kolompok umur 25-29 tahun sebesar 70.2\%, dan yang terendah terdapat pada kelompok umur 45-49 tahun sebesar $25 \%$. Namun demikian, dari hasil uji statistik tidak ada nilai $p$ value $<0.05$ yang berarti tidak ada hubungan antara usia dengan persepsi body image pada tenaga kesehatan di RSUD Meuraxa Kota Banda Aceh.

Tabel 2. Faktor-faktor yang berhubungan dengan body image tenaga kesehatan

\begin{tabular}{|c|c|c|c|c|c|c|c|c|}
\hline \multirow{3}{*}{ Faktor-Faktor Penyebab } & \multicolumn{4}{|c|}{ Persepsi Body image } & \multirow{2}{*}{\multicolumn{2}{|c|}{ Total }} & \multirow{3}{*}{$\begin{array}{c}\text { OR } \\
(95 \% \mathrm{Cl})\end{array}$} & \multirow{3}{*}{ Nilai $p$} \\
\hline & \multicolumn{2}{|c|}{ Positif } & \multicolumn{2}{|c|}{ Negatif } & & & & \\
\hline & $f$ & $\%$ & $f$ & $\%$ & $f$ & $\%$ & & \\
\hline \multicolumn{9}{|l|}{ Jenis Kelamin } \\
\hline Laki-laki & 22 & 62.9 & 13 & 37.1 & 35 & 100 & & \\
\hline Perempuan & 56 & 35.9 & 100 & 64.1 & 156 & 100 & $3(1.41-6.45)$ & 0.004 \\
\hline \multicolumn{9}{|l|}{ Usia } \\
\hline Di atas 50 Tahun & 1 & 50.0 & 1 & 50.0 & 2 & 100 & & \\
\hline 45-49 Tahun & 3 & 75.0 & 1 & 25.0 & 4 & 100 & $0.3(0.00-11.93)$ & 0.547 \\
\hline 40-44 Tahun & 22 & 73.3 & 8 & 26.7 & 30 & 100 & $0.4(0.02-6.52)$ & 0.492 \\
\hline 35-39 Tahun & 13 & 30.9 & 29 & 69.1 & 42 & 100 & $2.2(0.12-38.48)$ & 0.581 \\
\hline 30-34 Tahun & 22 & 39.3 & 34 & 60.7 & 56 & 100 & $1.5(0.09-26.01)$ & 0.762 \\
\hline 25-29 Tahun & 17 & 29.8 & 40 & 70.2 & 57 & 100 & $2.4(0.13-39.84)$ & 0.553 \\
\hline \multicolumn{9}{|l|}{ Perilaku Konsumsi } \\
\hline Positif & 76 & 60.8 & 49 & 39.2 & 125 & 100 & & \\
\hline Negatif & 2 & 3.0 & 64 & 97.0 & 66 & 100 & $49(11.61-21.11)$ & 0.0001 \\
\hline \multicolumn{9}{|l|}{ Kondisi Medis } \\
\hline Baik & 70 & 41.9 & 97 & 58.1 & 167 & 100 & & \\
\hline Kurang Baik & 8 & 33.3 & 16 & 66.7 & 24 & 100 & $1.4(0.58-3.55)$ & 0.426 \\
\hline \multicolumn{9}{|l|}{ Hubungan Interpersonal } \\
\hline Baik & 72 & 44.4 & 90 & 55.6 & 162 & 100 & & \\
\hline Kurang Baik & 6 & 20.7 & 23 & 79.3 & 29 & 100 & $3.0(1.18-7.93)$ & 0.021 \\
\hline Jumlah & 78 & 40.8 & 113 & 59.2 & 191 & 100 & & \\
\hline
\end{tabular}

Selanjutnya, berdasarkan variabel perilaku konsumsi makanan maka persepsi body image kategori positif lebih banyak dijumpai pada perilaku konsumsi makanan kategori positif dengan persentase $60.8 \%$ jika dibandingkan perilaku konsumsi makanan kategori negatif dengan persentase $3.0 \%$. Sementara itu, sebaliknya persepsi body image kategori negatif lebih banyak dijumpai pada perilaku konsumsi makanan kategori negatif dengan persentase $97.0 \%$ jika dibandingkan perilaku konsumsi makanan kategori positif dengan persentase $39.2 \%$. Hasil uji statistik menunjukkan 
responden dengan perilaku konsumsi makanan negatif berisiko mengalami persepsi body image negatif sebanyak 49 kali jika dibandingkan dengan perilaku konsumsi makanan positif. Nilai $p=0.0001$ yang berarti ada hubungan yang signifikan antara perilaku konsumsi makanan dengan persepsi body image pada tenaga kesehatan di RSUD Meuraxa Kota Banda Aceh.

Sedangkan menurut variabel kondisi medis, menunjukkan bahwa persepsi body image kategori positif lebih banyak dijumpai pada kondisi medis kategori baik dengan persentase $41.9 \%$ jika dibandingkan kondisi medis kategori kurang baik dengan persentase 33.3\%. Sementara itu, sebaliknya persepsi body image kategori negatif lebih banyak dijumpai pada kondisi medis kategori kurang baik dengan persentase $66.67 \%$ jika dibandingkan kondisi medis kategori baik dengan persentase $58.08 \%$. Namun demikian, hasil uji statistik menunjukkan nilai probabilitas sebesar 0.426 ( $p>0.05$ ) yang berarti tidak ada hubungan antara kondisi medis dengan persepsi body image pada tenaga kesehatan di RSUD Meuraxa Kota Banda Aceh.

Terakhir yaitu variabel hubungan interpersonal, hasil penelitian (tabel 2) menunjukkan bahwa persepsi body image kategori positif lebih banyak dijumpai pada hubungan interpersonal kategori baik dengan persentase $44.4 \%$ jika dibandingkan hubungan interpersonal kategori kurang baik dengan persentase $20.7 \%$.
Sementara itu, sebaliknya persepsi body image kategori negatif lebih banyak dijumpai pada hubungan interpersonal kategori kurang baik dengan persentase $79.3 \%$ jika dibandingkan hubungan interpersonal kategori baik dengan persentase $55.6 \%$. Hasil uji statistik menunjukkan hubungan interpersonal kategori kurang baik berisiko 3 kali mengalami persepsi body image negatif jika dibandingkan dengan hubungan interpersonal kategori baik. Sementara itu nilai $p$ value yang dihasilkan sebesar 0.021 yang berarti ada hubungan antara hubungan interpersonal dengan persepsi body image pada tenaga kesehatan di RSUD Meuraxa Kota Banda Aceh.

Hasil analisis multivariat sebagaimana disajikan pada tabel 3, menunjukkan bahwa responden dengan perilaku konsumsi makanan negatif berisiko 82 kali mengalami persepsi body image negatif jika dibandingkan dengan kategori positif. Sementara itu, responden dengan kondisi medis kurang baik berisiko 14 kali mengalami persepsi body image negatif jika dibandingkan dengan kategori baik. Selanjutnya pada variabel usia, kelompok usia 35-39 tahun berisiko 84 kali dan kelompok usia 30-34 tahun 54 kali serta kelompok usia 25-29 tahun 74 kali berisiko mengalami persepsi body image negatif jika dibandingkan dengan usia 50 tahun ke atas. Terakhir, responden dengan jenis kelamin perempuan berisiko 3 kali mengalami persepsi body image negatif jika dibandingkan dengan laki-laki.

Tabel 3. Hasil analisis multivariat terhadap faktor-faktor yang mempengaruhi body image tenaga kesehatan

\begin{tabular}{llccc}
\hline \multicolumn{1}{c}{ Variabel } & \multicolumn{1}{c}{ Kategori } & OR & $95 \% \mathrm{Cl}$ & Nilai p \\
\hline Perilaku Konsumsi Makanan & $\begin{array}{l}\text { Positif } \\
\text { Negatif }\end{array}$ & 82.11 & $13.69-429.45$ & 0.0001 \\
& $\begin{array}{l}\text { Baik } \\
\text { Kundisi Medis }\end{array}$ & 14.39 & $1.8-190.24$ & 0.043 \\
Usia & $\begin{array}{l}\text { di Atas 50 Tahun } \\
\text { 35-39 Tahun }\end{array}$ & 84.76 & $5.74-1249.96$ & 0.001 \\
& $\begin{array}{l}\text { 30-34 Tahun } \\
\text { 25-29 Tahun } \\
\text { Laki-laki }\end{array}$ & 54.22 & $3.78-777.47$ & 0.003 \\
Jenis Kelamin & 74.81 & $5.23-1069.53$ & 0.001 \\
& Perempuan & 3.48 & $1.08-11.17$ & 0.036 \\
\hline
\end{tabular}

\section{Pembahasan}

Hubungan Faktor Jenis Kelamin dengan Body Image Jenis kelamin sering sekali menjadi salah satu alasan untuk mendiskreditkan orang lain maupun diri sendiri. Kasus tersebut pada umumnya dirasakan oleh kaum perempuan. Jika dilihat secara personal, perempuan biasanya lebih kritis terhadap tubuh mereka baik secara keseluruhan maupun pada bagian tertentu daripada laki-laki. Persepsi body image yang buruk sering berhubungan dengan kelebihan berat badan baik itu terlalu kurus atau 
terlalu gemuk (Cash \& Smolak, 2011). Hasil penelitian menunjukkan bawa persepsi body image kategori negatif lebih banyak dijumpai pada jenis kelamin perempuan dengan persentase $64.10 \%$ jika dibandingkan jenis kelamin laki-laki dengan persentase $37.14 \%$. Hasil uji statistik baik secara bivariat maupun multivariat menunjukkan bahwa perempuan berisiko 3 kali mengalami body image negatif jika dibandingkan dengan laki-laki.

Oliver and Lalik (2004) menyatakan bahwa jenis kelamin adalah faktor paling penting dalam perkembangan body image seseorang. Mereka menyebutkan bahwa perempuan lebih negatif memandang body image dibandingkan pria. Hasil penelitian ini sejalan dengan penelitian Brennan et al. (2010) mengenai perbedaan body image laki-laki dan perempuan, ditemukan hasil bahwa laki-laki memperoleh skor yang lebih tinggi dari perempuan mengenai skala body image. Hal ini mengindikasikan bahwa laki-laki lebih puas terhadap tubuh mereka dibandingkan perempuan. Namun demikian, penelitian yang dilakukan Margaretta and Rozali (2018) justru menghasilkan sebaliknya bahwa hasil dari penelitian ini adalah tidak adanya perbedaan yang signifikan pada body image ditinjau dari jenis kelamin. Dalam penelitiannya didapatkan bahwa terdapat $55.6 \%$ pria dan $53.3 \%$ wanita yang memiliki body image negatif. Sementara itu, $44.4 \%$ pria dan $46.7 \%$ wanita memiliki body image positif, yang berarti baik pria dan wanita persentase mengalami body image negatif sama-sama tinggi.

Dari fenomena tersebut peneliti berasumsi bahwa kecenderungan perempuan lebih tinggi persentase mengalami body image negatif dikarenakan perassan malu akan kondisi tubuhnya. Perempuan selalu ingin terlihat bagus dihadapan orang lain terutama dihadapan pasangannya. Sehingga ketika seorang perempuan ragu akan bentuk tubuhnya maka akan cepat menimbulkan kesan body image yang negatif. Berbeda dengan laki-laki dimana kebanyakan laki-laki tidak menghiraukan bentuk tubuhnya. Laki-laki lebih rilek dengan keadaan tubuhnya sehingga kesan body image yang negatif bisa di minimalisir.

\section{Hubungan Faktor Usia dengan Body Image}

Usia muda merupakan usia dimana setiap orang masih sangat memperhatikan penampilannya, terutama bentuk tubuhnya. Ketika bentuk tubuh tidak sesuai dengan harapan, pada usia muda kecenderungan akan terjadinya body image negatif sangat tinggi. Hasil penelitian menunjukkan bahwa terdapat perbedaan antara analisa bivariat dan uni variat. Secara bivariat, persepsi body image kategori positif lebih banyak dijumpai pada kelompok usia 45-49 tahun jika dibandingkan dengan kelompok usia lainnya. Persentase kelompok usia 45-49 tahun sebesar $75 \%$, dan yang terendah terdapat pada kelompok usia 25-29 tahun sebesar 29.82\%. Sementara itu, sebaliknya persepsi body image kategori negatif lebih banyak dijumpai pada kelompok umur 25-29 tahun jika dibandingkan dengan kelompok umur lainnya. Persentase kolompok umur 25-29 tahun sebesar $70.18 \%$, dan yang terendah terdapat pada kelompok umur 45-49 tahun sebesar $25 \%$. Namun demikian, dari hasil uji statistik tidak ada nilai $p$ value $<0.05$ yang berarti tidak ada hubungan antara usia dengan persepsi body image pada tenaga kesehatan di RSUD Meuraxa Kota Banda Aceh.

Hasil yang berbeda ditunjukkan pada saat analisa multivariat, dimana kelompok usia 35-39 tahun berisiko 84 kali dan kelompok usia 30-34 tahun 54 kali serta kelompok usia 25-29 tahun berisiko 74 kali mengalami persepsi body image negatif jika dibandingkan dengan usia 50 tahun ke atas. Hasil kedua analisa ini berarti bahwa usia responden bukan merupakan variabel yang independen mempengaruhi persepsi body image seseorang, hal tersebut dikarenakan usia akan memiliki hubungan jika variabel lain ikut dikontrol. Hasil tersebut sejalan dengan penelitian Ålgars et al. (2009) mendapatkan nilai signifikansi dibawah 0.004 yang mengidentifikasikan bahwa terdapat hubungan antara kelompok usia dengan persepsi body image pada pria dan wanita usia 18-49 tahun.

Dari hasil kedua analisa tersebut peneliti berasumsi bahwa ketika variabel usia hanya dihubungkan dengan persepsi body image maka tidak terlihat hubungannya secara statistik. Namun secara multivariat, hasil uji statistik memperlihatkan hubungan pada kelompok usia 3539 tahun, 30-34 tahun dan 25-29 tahun. Hasil tersebut didapatkan ketika pada tahap analisa multivariat, statistik melakukan analisa gabungan sehingga ketika variabel lain memiliki hubungan dengan body image, maka akan dibandingkan juga dengan variabel independen lainnya.

Santrock (2007) mengungkapkan bahwa salah satu aspek psikologis dari perubahan fisik pada usia muda adalah menjadi amat memperhatikan tubuh mereka dan membangun citranya sendiri mengenai bagaimana bentuk tubuh 
mereka. Perubahan fisik dan emosi yang tidak stabil seringkali menimbulkan ketidakpuasan citra tubuh dikalangan usia muda itu sendiri. Hasil penelitian Kim and Kang (2015) menunjukkan bahwa terdapat persamaan dimana usia lebih muda cenderung memiliki lebih banyak persepsi body image negatif namun secara statistik berbeda dari penelitian ini. Hasil penelitian Kim and Kang (2015) menunjukkan bahwa ada hubungan yang signifikan antara usia dengan kejadian body image negatif pada orang dewasa.

Dari hasil penelitian peneliti berasumsi bahwa seperti yang telah dijelaskan sebelumnya usia muda merupakan usia dimana seseorang sedang menunjukkan jati dirinya kepada publik, sehingga jika ada perubahan pada bentuk tubuh yang tidak diinginkan akan sangat berdampak pada body image yang negatif. Usia muda harus memiliki pola hidup sehat yang sangat ketat seperti menjaga pola makan dan melakukan aktifitas olah raga yang teratur sehingga bisa menjaga bentuk tubuh agar tetap normal dan menjaga persepsi body image tetap positif.

\section{Hubungan Faktor Perilaku Konsumsi Makanan dengan Body Image}

Mengkonsumsi makanan dengan gizi yang tidak seimbang akan mengakibatkan gangguan pada fungsi tubuh manusia. Mengkonsumsi makanan berlebih akan mengakibatkan penumpukan zat-zat makanan dalam tubuh sebaliknya mengkonsumsi makanan yang kurang akan mengakibatkan tubuh seseorang kekurangan nutrisi. Hasil penelitian menunjukkan bahwa persepsi body image kategori negatif lebih banyak dijumpai pada prilaku konsumsi makanan kategori negatif dengan persentase $96.97 \%$ jika dibandingkan perilaku konsumsi makanan kategori positif dengan persentase $39.20 \%$. Hasil uji statistik menunjukkan responden dengan perilaku konsumsi makanan negatif berisiko mengalami persepsi body image negatif sebanyak 49 kali jika dibandingkan dengan perilaku konsumsi makanan positif. Nilai $\mathrm{p}$ value sebesar 0.0001 yang berarti ada hubungan yang signifikan antara perilaku konsumsi makanan dengan persepsi body image pada tenaga kesehatan di RSUD Meuraxa Kota Banda Aceh.

Risiko responden mengalami body image negatif dikarenakan perilaku konsumsi makanan yang negatif bertambah ketika dilakukan analisa secara multivariat. Hasil uji multivariat menunjukkan bahwa responden dengan konsumsi makanan kurang baik berisiko sebesar 82 kali mengalami body image negatif jika dibandingkan dengan perilaku konsumsi makanan positif. Hasil tersebut mengidentifikasikan bahwa variabel konsumsi makanan merupakan variabel yang benar-benar independen mempengaruhi persepsi body image pada tenaga kesehatan di RSUD Meuraxa Kota Banda Aceh.

Perilaku makan merupakan perilaku paling penting yang dapat mempengaruhi keadaan gizi. Hal ini disebabkan karena kuantitas dan kualitas makanan dan minuman yang dikonsumsi akan mempengaruhi asupan gizi seseorang. Gizi baik membuat berat badan normal sehingga dapat menghindari seseorang dengan persepsi body image yang negatif (Kemenkes, 2014). Penelitian terkait hubungan perilaku makan dengan body image hingga saat ini sangat sulit untuk ditemukan, hal ini juga disampaikan oleh Kilpela et al. (2015) yang bahwa perilaku makan yang tidak teratur atau gangguan makanan sedikitnya akan berpengaruh pada persepsi body image. Namun demikian, penelitian terkait hal tersebut masih harus dilakukan lagi secara mendalam. Terkait dalam konteks perilaku makanan dan persepsi body image, penelitian Teixeira et al. (2016) pada anak sekolah menengah menghasilkan bahwa semakin tinggi skor perilaku makan pada anak maka semakin tinggi ketidak puasan terhadap body image.

Dari hasil penelitian di atas, peneliti berasumsi bahwa pola makanan yang tidak sehat akan mengakibatkan asupan gizi yang tidak sehat. Asupan gizi yang tidak sehat akan berdampak pada tubuh seseorang baik itu kelebihan maupun kekurangan berat badan. Bagi individu yang tidak siap menerima keadaan tersebut, maka akan mengakibatkan ketidak puasan atau persepsi body imagenya menjadi negatif.

\section{Hubungan Faktor Kondisi Medis dengan Body Image} Kondisi medis terkadang sangat berdampak pada perubahan tubuh seseorang. Seseorang yang terkena penyakit menahun misalnya akan mempengaruhi masa tubuh sehingga terlihat lebih kurus dan lain-lain sehingga akan menyebabkan ketidak puasan akan kondisi tubuhnya tersebut. Namun demikian, hasil penelitian menunjukkan bahwa nilai statistik menunjukkan $p$ value sebesar 0.426 yang berarti tidak ada hubungan antara kondisi medis dengan persepsi body image pada tenaga kesehatan di RSUD Meuraxa Kota Banda Aceh. hasil tersebut berbeda secara multivariat. 
Setelah dimasukkan kedalam model regresi logistik menggunakan perintah stepwise, kondisi medis menjadi memiliki hubungan namun secara $p$ value tidak begitu signifikan. Namun demikian, kondisi medis kurang baik berisiko 14 kali akan mengalami persepsi body image negatif jika dibandingkan dengan kondisi medis baik.

Kilpela et al. (2015) menyatakan bahwa setiap penyakit yang diderita seseorang akan berdampak pada persepsi body imagenya, dimana wanita lebih berisiko untuk mengalaminya dikarenakan wanita lebih rentan terkena suatu penyakit yang berhubungan langsung dengan perubahan tubuh. Penelitian Wardani et al. (2015) menghasilkan kesimpulan yang berbeda dari penelitian ini dimana terdapat hubungan kondisi obesitas responden dengan body image negatif dengan signifikansinya lebih kecil dari 0.01 .

Dari hasil penelitian peneliti berasumsi bahwa kondisi medis tidak serta merta akan mempengaruhi body image seseorang. Akan tetapi, ada beberapa kriteria kondisi medis yang berhubungan dengan body image seperti kondisi medis yang akan mengubah bentuk tubuh dari penderitanya. Misalnya, penyakit menahun yang membuat badan terlihat kurus, adanya operasi pada anggota tubuh yang secara langsung mengubah bentuk tubuh penderita.

\section{Hubungan Faktor Interpersonal dengan Body Image}

Pikiran dan perasaan mengenai tubuh bermula dari adanya reaksi orang lain. Dalam konteks perkembangan, gambaran tubuh berasal dari hubungan interpersonal. Perkembangan emosional dan pikiran individu juga berkontribusi pada bagaimana seseorang melihat dirinya. Maka, bagaimana seseorang berfikir dan merasa tubuhnya dapat mempengaruhi hubungan dan karakteristik psikologis (Chase, 2001). Hasil penelitian menunjukkan bahwa persepsi body image kategori negatif lebih banyak dijumpai pada hubungan interpersonal kategori kurang baik dengan persentase $79.31 \%$ jika dibandingkan hubungan interpersonal kategori baik dengan persentase $55.56 \%$. Hasil uji statistik menunjukkan hubungan interpersonal kategori kurang baik berisiko 3 kali mengalami persepsi body image negatif jika dibandingkan dengan hubungan interpersonal kategori baik. Dengan nilai signifikansi sebesar 0.021 maka ada hubungan antara hubungan interpersonal dengan persepsi body image pada tenaga kesehatan di RSUD Meuraxa Kota Banda Aceh.

Memahami hakikat hubungan interpersonal harus dilakukan dengan baik. Seseorang dengan komunikasi interpersonal yang baik cenderung akan mendapatkan kepercayaan diri yang lebih jika dibandingkan dengan hubungan interpersonal yang kurang baik. Hal tersebut dikarenakan seseorang dengan hubungan interpersonal tidak baik akan menganggu proses komunikasi sehingga tidak jarang individu tersebut menjadi minder dan kurang pergaulan. Individu yang seperti itu biasanya sangat sensitif dengan lingkungan sekitar dan tidak percaya diri dimana kondisi tersebut secara tidak langsung akan mempengaruhi persepsi body imagenya (Sari, 2017).

Berdasarkan hasil penelitian tersebut, peneliti berasumsi bahwa individu dengan hubungan interpersonal yang kurang baik cenderung akan minder. Seseorang dengan sifat minder sering kali akan memperhatikan kondisi tubuhnya agar tidak menjadi pusat perhatian orang lain. Sehingga, ketika terjadi perubahan bentuk tubuhnya maka akan meyebabkan terjadinya persepsi body image yang negatif.

\section{Kesimpulan}

Secara umum persepsi body image negatif lebih banyak ditemukan pada perempuan dan pada usia 25-29 tahun. Faktor-faktor yang berhubungan dengan body image tenaga kesehatan yaitu faktor jenis kelamin, perilaku konsumsi makanan, hubungan interpersonal. Sedangkan faktor umur dan kondisi medis tidak menunjukkan hubungan dengan body image. Faktor dominan penyebab body image yaitu perilaku konsumsi pada tenaga kesehatan RSUD Meuraxa Kota Banda Aceh.

Saran, tenaga kesehatan berjenis kelamin perempuan memiliki risiko lebih besar mengalami persepsi body image negatif oleh karena itu peneliti menyarankan untuk terus menjaga pola hidup sehat agar terbebas dari segala jenis penyakit yang bisa berdampak pada memburuknya persepsi body imagenya sendiri. Selanjutnya, rumah sakit perlu membuat kebijakan mengenai penanggulangan permasalahan body image di kalangan petugas medis dalam rangka menjaga kualitas layanan kesehatan tetap maksimal. 


\section{Deklarasi Konflik Kepentingan}

Penelitian ini tidak menyertakan konflik kepentingan penulis maupun potensi konflik kepentingan instansi sehubungan dengan penelitian yang telah dilakukan, baik berdasarkan kepengarangan, maupun publikasi.

\section{Ucapan Terima Kasih}

Pada kesempatan ini, penulis mengucapkan terima kasih kepada kepada Direktur Rumah Sakit Umum Meuraxa Banda Aceh yang telah membantu proses pelaksanaan penelitian ini dan memberikan ijin untuk pelaksanaan penelitian. Selain itu, juga ucapana terima kasih disampaikan kepada para tenaga kesehatan selaku responden yang telah bersedia terlibat secara langsung dalam penelitian ini.

\section{Daftar Rujukan}

Abbate, C., Giorgianni, C., Munao, F., Beninato, G., D'Arrigo, G., D'Arrigo, P., \& Brecciaroli, R. (2006). Evaluation of obesity In healthcare workers. Med Lav, 97(1), 13-19.

Ålgars, M., Santtila, P., Varjonen, M., Witting, K., Johansson, A., Jern, P., \& Sandnabba, N. K. (2009). The adult body: how age, gender, and body mass index are related to body image. Journal of aging and health, 21(8), 1112-1132.

Atwater, Eastwood, \& Karen, G., D. (2005). Psychology for living (adjustment, growth and behaviour today) (2 ed.). Pearson Prentice Hall.

Bert, H., Jr,, \& Panek, P., E. (1989). Adult Development and Aging. Harper \& Row Publishers.

Brennan, M. A., Lalonde, C. E., \& Bain, J. L. (2010). Body image perceptions: Do gender differences exist. Psi Chi Journal of Undergraduate Research, 15(3), 130-138.

Brown, I., Stide, C., Psarou, A., Brewins, L., \& Thompson, J. (2007). Management of obesity in primary care: Nurses' practices, beliefs and attitudes. J Adv Nurs, 59, 329341.

Budhiarta, i., \& Muttaqin. (2019). Model HSQMetrix: untuk pengukuran kualitas pelayanan kesehatan dan rumah sakit di Banda Aceh. CV. Penerbit Qiara Media.

Cash, T., F,, \& Henry, P., E. (1995). Women's Body Image: The Result of a National Survey in the U.S.A. Sex Roles. 33(1/2), 19-28.

Cash, T., F,, \& Pruzinsky, T. (2002). Future challenges for body image theory, research, and clinical practice. In Body image. A handbook of theory, research, and clinical practice (Vol. 509-516). The Guilford Press.

Cash, T., F. (1994). Body Image Attitudes : Evaluation, Investment and Affect: Perceptual Motor Skills. Journal of psychology, 78, 1168-1170.

Cash, T. F., \& Smolak, L. (2011). Body image: A handbook of science, practice, and prevention. Guilford Press.

Devi, T., P, S, \& Dian, R., S. (2015). Hubungan Antara Citra Tubuh Dengan Pengungkapan Diri Pada Remaja Awal Kelas VII. Jurnal Empati, 4(2), 14-19.

Ghozali, I. (2011). Aplikasi analisis multivariate dengan program SPSS. Badan Penerbit Universitas Diponegoro.

Gila, A., Castro, J., Toro, J., \& Salamero, M. (2004). Subjective body image dimensions in normal female population: evolution through adolescence and early adulthood. International Journal of Psychology and Pshchological Theraphy, 4(1), 1-10.

Haugaard, J., J. (2001). Problematic behaviors during adolescence. McGraw-Hill.

Heinberg, L., Wood, K., C,, \& Thompson, K. (1995). Body Image. In: Rinkert, Vaughn. Adolescent nutrition assasment and management. AChapmann \& Hall.

Hubley, A. M., \& Quinlan, L. (2003). Body Image In Men And Women Across The Adult Lifespan. Paper presented at the VIII European Congress of Psychology. Vienna, Austria, 1-7.

Hurlock, E., B. (1980). Perkembangan Suati Pendekatan Sepanjang Rentang Kehidupan Erlangga.

Kemenkes, R. (2014). Pedoman gizi seimbang. Jakarta: Kemenkes RI.

Kilpela, L. S., Becker, C. B., Wesley, N., \& Stewart, T. (2015). Body image in adult women: Moving beyond the younger years. Advances in Eating Disorders: Theory, Research and Practice, 3(2), 144-164. 
Kim, J. S., \& Kang, S. (2015, Jun). A Study on Body Image, Sexual Quality of Life, Depression, and Quality of Life in Middle-aged Adults. Asian Nurs Res (Korean Soc Nurs Sci), 9(2), 96-103.

https://doi.org/10.1016/j.anr.2014.12.001

Margaretta, A., \& Rozali, Y. A. (2018). Perbedaan Body Image Ditinjau Dari Jenis Kelamin Pada Anggota Clark Hatch Fitness Center. Mahasiswa Fakultas Psikologi Universitas Esa Unggul, 903.

McArthur, L., \& Ross, J. (1997). Attitudes of registered dietitians toward personal overweight and overweight clients. Journal of The American Dietetic Association, 97(1), 63-66.

Notoatmodjo, S. (2003). Pendidikan dan Perilaku Kesehatan. PT. Rineka Cipta.

Nunez, N., C,, Ochoa, V., U,, Solares, N., J, C,, Solares, C., J,, Cardenas, V., M,, \& Campos, A. (2005). Overweight and obesity among health-professional woman. Ginecol Obstet Mex, 73(8), 401-406.

Oliver, K. L., \& Lalik, R. (2004). Critical inquiry on the body in girls' physical education classes: A critical poststructural perspective. Journal of teaching in physical education, 23(2), 162-195.

Roberts, M. L., Zonfrillo, M. R., Yu, S., Dziura, J. D., \& Spiro, D. M. (2013). Overweight physicians during residency: a cross-sectional and longitudinal study. Journal of graduate medical education, 5(3), 405-411.

RSUD Meuraxa. (2019). Data Pegawai RSUD Meuraxa Kota Banda Aceh.
Santrock, J., W. (2002). Life-Span Development: Perkembangan Masa Hidup, Edisi 5 Jilid II. Erlangga.

Santrock, J. W. (2007). Adolescence : Perkembangan Remaja (S. Saragih, Trans.; Vol. 2). Erlangga.

Sari, A. A. (2017). Komunikasi antarpribadi. Deepublish.

Skall, L., \& Pengpid, S. (2011). Obesity and health problems among south African healthcare workers: do healthcare workers take care of themselves. J South Africa Family Practice, 53(6), 563-567.

Sumantri, S. (2011). Metodelogi Penelitian Kesehatan. Pranada Media.

Teixeira, M. D., Pereira, A. T., Marques, M. V., Saraiva, J. M., \& Macedo, A. F. d. (2016). Eating behaviors, body image, perfectionism, and self-esteem in a sample of Portuguese girls. Brazilian Journal of Psychiatry, 38(2), 135-140.

Thompson, J., K,, Leslie, J., Heinberg, Altabe, \& Stacey, T., D,. (1999). Exacting Beauty. American Psychological Association.

Thompson, J., K. (2000). Body Image, Eating Disorders, and Obesity. Washington, DC.

Wardani, D. A. K., Huriyati, E., Mustikaningtyas, M., \& Hastuti, J. (2015). Obesitas, body image, dan perasaan stres pada mahasiswa di Daerah Istimewa Yogyakarta. Jurnal Gizi Klinik Indonesia, 11(4), 161-169.

Wright, J. (1998). Female nurses' perception of acceptable female body size: an exploratory study. J Clin Nurs, 7(4), 307-3145.

Ziebland, S., Robertson, J., Jay, J., \& Neil, A. (2002). Body Image And Weight Change In Middle Age: A Qualitative Study International. Journal of Obesity, 26, 1083-1091. 